\title{
The stability of imine-containing dynamic [2]rotaxanes to hydrolysis $\uparrow$
}

\author{
Ken Cham-Fai Leung, ${ }^{* a, b}$ Wing-Yan Wong, ${ }^{a}$ Fabio Aricó, ${ }^{b}$ Philip C. Haussmann ${ }^{b}$ and J. Fraser Stoddart*b,c
}

\author{
Received 3rd August 2009, Accepted 8th October 2009 \\ First published as an Advance Article on the web 20th November 2009 \\ DOI: 10.1039/b915864b
}

Large amounts ( $>100$ mol equivalents) of water are required to effect by hydrolysis the partial disassembly of the rings from the dumbbell components of two dynamic [2]rotaxanes. The two dynamic [2] rotaxanes are comprised of [24]crown-8 rings - each of which incorporate two imine bonds - encircling a dumbbell component composed of a dibenzylammonium ion in which each of the two benzyl substituents carries two methoxyl groups attached to their 3- and 5-positions. A mechanism for the partial disassembly of the two dynamic [2]rotaxanes, involving the cleavage of the kinetically labile imine bonds by water molecules, is proposed. The most important experimental observation to be noted is the fact that the hydrolysis of the macrocyclic diimines, associated with the templating

$-\mathrm{CH}_{2} \mathrm{NH}_{2}{ }^{+} \mathrm{CH}_{2}$-centres in the middle of their dumbbells, turns out to be an uphill task to perform in the face of the molecular recognition provided by strong $\left[\mathrm{N}^{+}-\mathrm{H} \cdots \mathrm{O}\right]$ hydrogen bonds and weaker, yet not insignificant, $[\mathrm{C}-\mathrm{H} \cdots \mathrm{O}]$ interactions. The dynamic nature of the imine bond formation and hydrolysis is such that the acyclic components produced during hydrolysis of the imine bonds can be enticed to cyclise once again around the $-\mathrm{CH}_{2} \mathrm{NH}_{2}{ }^{+} \mathrm{CH}_{2}$-template, affording the [2]rotaxanes. The reluctance of imine bonds, present in substantial numbers in larger molecular and extended structures, is significant when it comes to exercising dynamic chemistry in compounds where multiple imine bonds are present.

\section{Introduction}

Recently, dynamic covalent chemistry ${ }^{1}$ (DCC) has attracted increasing attention on account of its usefulness in preparing complex products, such as molecular Borromean rings, ${ }^{2}$ dendrimers $^{3}$ and other exotic compounds ${ }^{4}$ with high efficiencies using onepot, templated self-assembly processes. ${ }^{5}$ The nearly quantitative formation of the (super)structures with mechanically intertwined and interlocked entities indicates that a template effect ${ }^{5 a}$ is highly efficient, yielding thermodynamically stable supramolecular intermediates on the way to the desired entities. The main advantage of the thermodynamic process over the kinetic one is that the former operates under equilibrium control such that the formation of undesired, kinetically competitive intermediates can eventually make their way back to the most energetically-favored product by means of error checking and proof-reading. ${ }^{1 g}$ DCC relies upon the use of dynamic covalent bonds that form in a reversible manner. Common dynamic equilibrating (reversible) reactions exploited in such syntheses include olefin metathesis, ${ }^{6}$ and disulfide ${ }^{7}$ and imine formation. ${ }^{8}$

Generally, imines are relatively unstable since they are susceptible to rapid hydrolysis in the presence of water. ${ }^{9}$ Saggiomo and Lüning ${ }^{10}$ have reported recently, however, that imine-

${ }^{a}$ Center of Novel Functional Molecules, Department of Chemistry, The Chinese University of Hong Kong, Shatin, NT, Hong Kong SAR, P. R. China. E-mail: cfleung@cuhk.edu.hk; Fax: (+852)2603-5057

${ }^{b}$ California NanoSystems Institute and Department of Chemistry and Biochemistry, The University of California, Los Angeles, 405 Hilgard Avenue, Los Angeles, California, 90095, USA

'Department of Chemistry, Northwestern University, 2145 Sheridan Road, Evanston, Illinois, 60208, USA. E-mail: stoddart@northwestern.edu; Fax: (+1) 847-491-1009

$\dagger$ Electronic supplementary information (ESI) available: NMR and mass spectra. See DOI: $10.1039 /$ b915864b containing macrocycles possess remarkable stabilities in the presence of water. Other molecular systems, ${ }^{11}$ involving dative bonds between imines and transition metal ions, ${ }^{12}$ can also experience increased imine stabilities in water. It follows that a careful investigation of the dissociative mechanisms associated with the formation and hydrolysis of dynamic rotaxanes containing imine bonds is important in the context of the design of functional rotaxanes ${ }^{13}$ that can be obtained in high yields by DCC and possess potentially useful applications. ${ }^{14}$

In this paper, we report an investigation of the dissociation of dynamic, imine-containing rotaxanes ${ }^{8 a}$ in the presence of an excess of water. It transpires that not only is the hydrolysis far from complete, but also that the dissociated molecular components obtained at equilibrium can be assembled rather easily to afford the original [2]rotaxanes by removing the water from the aqueous solutions with appropriate drying agents.

\section{Results and discussion}

By employing DCC associated with reversible imine bond formation, we reported ${ }^{8 c}$ previously that the dynamic [2]rotaxane 1a- $\mathrm{H} \cdot \mathrm{PF}_{6}$ can be formed (Scheme 1) by condensation between three different components in a $1: 1: 1$ ratio-the diformylpyridine $\mathbf{2}$, the diamine $\mathbf{3 a}$ and the already stoppered dialkylammonium salt $4-\mathrm{H} \cdot \mathrm{PF}_{6}$ - in dry $\mathrm{MeCN}(60 \mathrm{mM})$ in over $90 \%$ yield in one pot. Similarly, another dynamic [2] rotaxane $\mathbf{1 b}-\mathrm{H} \cdot \mathrm{PF}_{6}$ can also be formed using the same condensation method with $\mathbf{2}$, the diamine $\mathbf{3 b}$ and $\mathbf{4}-\mathrm{H} \cdot \mathrm{PF}_{6}$ in a $1: 1: 1$ ratio. Moreover, we found out experimentally that the condensations occur effectively in both $\mathrm{MeCN}$ and $\mathrm{MeNO}_{2}(60 \mathrm{mM})$. The encirclement of a dialkylammonium ion by the imine-containing [24]crown-8 macrocycle can be regarded as a thermodynamically controlled template-directed self-assembly and amplification process. Since 

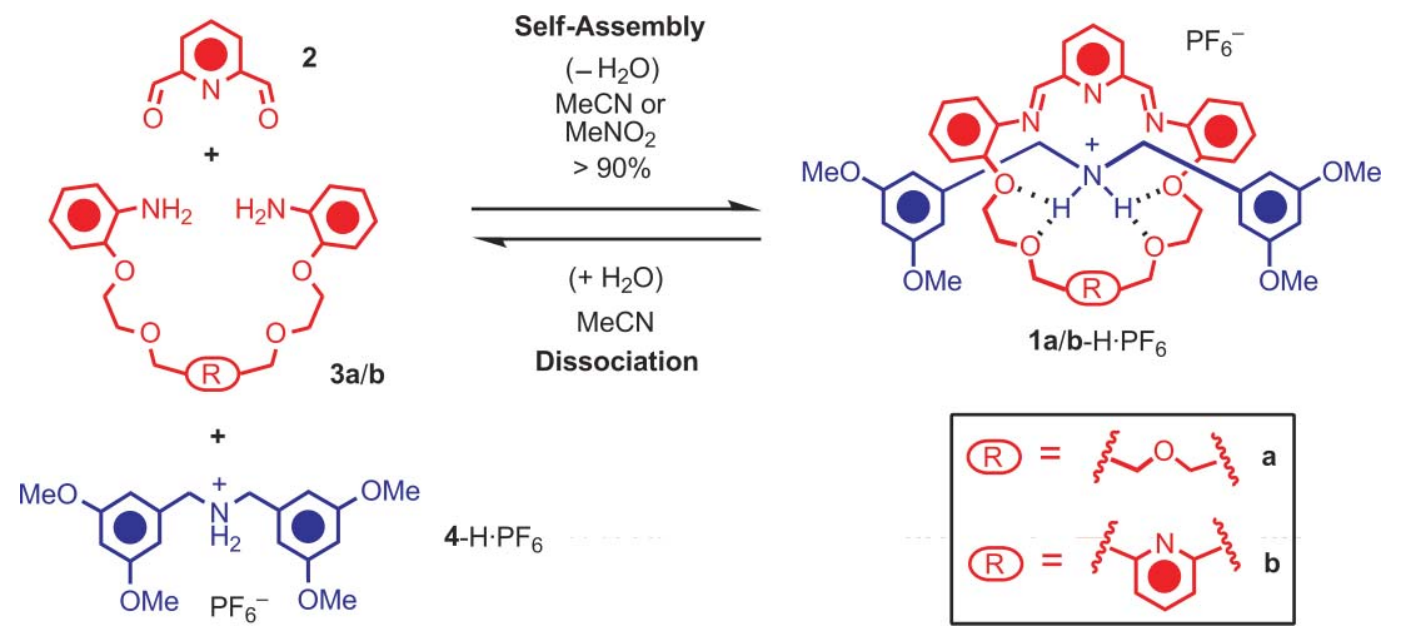

Scheme 1 Equilibrium for the self-assembly and dissociation of the dynd
depending on the concentration of water present in the reaction mixture.

the dialkylammonium ion template $4-\mathrm{H} \cdot \mathrm{PF}_{6}$ fits well into the macrocycle, which is generated from the $[1+1]$ condensation between $\mathbf{2}$ and $\mathbf{3 a} / \mathbf{b}$, the [2] rotaxanes $\mathbf{1 a} / \mathbf{b}-\mathbf{H} \cdot \mathbf{P F}_{6}$ can be amplified as the major products in the dynamic competitive equilibrium mixture. Subsequently, the [2] rotaxanes $\mathbf{1 a} / \mathbf{b}-\mathrm{H} \cdot \mathrm{PF}_{6}$ were characterised by ${ }^{1} \mathrm{H}$ NMR spectroscopy and matrix-assisted laser-desorption ionization mass spectrometry (HR-MALDI-MS) (mass spectra not shown). The ${ }^{1} \mathrm{H}$ NMR spectra were obtained after 15 min of mixing between the free components. The ${ }^{1} \mathrm{H}$ NMR spectra of the dynamic [2]rotaxanes reveal that the characteristic benzylic methylene proton signals, adjacent to the ammonium ion centre, observed at $3.8-3.9 \mathrm{ppm}$ of $4-\mathrm{H} \cdot \mathrm{PF}_{6}$ are shifted downfield to 4.5-4.6 ppm upon rotaxane formation. Moreover, the characteristic peaks for the protons on the ethyleneglycol chain are shifted upfield (see the ESI $\dagger$ ). The [2]rotaxanes are stable entities on account of $\left[\mathrm{N}^{+}-\mathrm{H} \cdots \mathrm{O}\right]$ and $\left[\mathrm{N}^{+}-\mathrm{C}-\mathrm{H} \cdots \mathrm{X}\right](\mathrm{X}=\mathrm{O}$ or $\mathrm{N})$ hydrogen bonds, in addition to electrostatic and $\pi-\pi$ stacking interactions. ${ }^{8 c}$ Thereafter, they were redissolved in MeCN prior to carrying out dissociation studies in the presence of different amounts of water.

Our investigations have shown that the dissociation of dynamic [2]rotaxanes $\mathbf{1 a} / \mathbf{b}-\mathrm{H} \cdot \mathrm{PF}_{6}$ requires large amounts of water. Thus, ${ }^{1} \mathrm{H}$ NMR spectroscopy was employed for investigating the dissociation of $\mathbf{1 a} / \mathbf{b}-\mathrm{H} \cdot \mathrm{PF}_{6}$, following addition ${ }^{15}$ of $100,200,250$ and 500 equivalents of $\mathrm{D}_{2} \mathrm{O}$. Whether or not equilibration has been reached, sharp signals in the ${ }^{1} \mathrm{H}$ NMR spectra of the [2]rotaxanes indicate that they are relatively stable kinetically on the NMR timescale at $500 \mathrm{MHz}$. The stability is presumably the result of the stabilizing multiple noncovalent bonding interactions. By way of an example, Fig. 1 shows the stacked ${ }^{1} \mathrm{H}$ NMR spectra $(500 \mathrm{MHz}$, $\mathrm{CD}_{3} \mathrm{CN}, 298 \mathrm{~K}$, aromatic region, $16.6 \mathrm{mM}, \mathrm{b}=$ bound rotaxane and $\mathrm{f}=$ free components) of the [2] rotaxane $\mathbf{1 a}-\mathrm{H} \cdot \mathrm{PF}_{6}$ in the presence of 200 equivalents of $\mathrm{D}_{2} \mathrm{O}$. Initially, the NMR spectra of [2] rotaxane $\mathbf{1 a}-\mathrm{H} \cdot \mathrm{PF}_{6}$ (at $0 \mathrm{~min}$ ) reveal the proton signals at $\delta=7.71 \mathrm{ppm}$ and $\delta=8.02 \mathrm{ppm}$ for the bound (b) pyridine ring, at $\delta=6.9-7.5 \mathrm{ppm}$ for the bound (b) N,O-substituted aryl ring, and at $\delta=6.10 \mathrm{ppm}$ and $\delta=6.45 \mathrm{ppm}$ for the bound (b) dimethoxyaryl ring. With increasing time in the presence of water, the characteristic proton signals originating from the aldehyde
( $\delta=10.12 \mathrm{ppm})$, the free (f) pyridine $\operatorname{ring}(\delta=8.22 \mathrm{ppm})$ and the free (f) dimethoxyaryl ring ( $\delta=6.58$ and $6.62 \mathrm{ppm})$ in separate cyclic (or acyclic) and dumbbell components were found to have their relative intensities increase, while those signals arising from the rotaxane decreased. The low intensity aldehyde signal at $10.10 \mathrm{ppm}$ can be attributed to the intermediate monoaldehyde $\mathbf{5 a} / \mathbf{b}$ formed during the hydrolysis of $\mathbf{1 a} / \mathbf{b}-\mathrm{H} \cdot \mathrm{PF}_{6}$. The results indicate that the dynamic [2] rotaxane dissociates slowly into its free components $-\mathbf{2}$, 3a and $\mathbf{4}-\mathrm{H} \cdot \mathrm{PF}_{6}$ - until the dissociation process has reached equilibrium after $24 \mathrm{~h}$. Furthermore, the broad signal $(\delta=9.98 \mathrm{ppm})$ for the $\mathrm{NH}_{2}{ }^{+}$centre became diminished with time on account of proton/deuterium exchange. With particular reference to $\mathbf{1 a}-\mathrm{H} \cdot \mathrm{PF}_{6}$, there were 52,41 and $14 \%$ of the dynamic [2]rotaxane remaining in the mixture after $24 \mathrm{~h}$ following the additions, in turn, of 100,200 and 500 equivalents of $\mathrm{D}_{2} \mathrm{O}$. On the other hand, in the case of the dissociation of $\mathbf{1 b}-\mathrm{H} \cdot \mathrm{PF}_{6}$, there were 19,8 and $4 \%$ of the dynamic [2]rotaxane remaining in the mixture after $24 \mathrm{~h}$ following the additions, in turn, of 100, 250 and 500 equivalents of $\mathrm{D}_{2} \mathrm{O}$. Moreover, the ${ }^{1} \mathrm{H}$ NMR spectra reveal that the residual dynamic [2] rotaxanes $\mathbf{1 a} / \mathbf{b}-\mathbf{H} \cdot \mathrm{PF}_{6}$ are stable in the $\mathrm{CD}_{3} \mathrm{CN}-\mathrm{D}_{2} \mathrm{O}$ mixture after $24 \mathrm{~h}$, reflecting a situation that is able to maintain the integrity of the [2]rotaxane constitution, even in the presence of water.

By comparing the integrations of characteristic signals arising from the dynamic rotaxanes $\mathbf{1 a} / \mathbf{b}-\mathrm{H} \cdot \mathrm{PF}_{6}$ and the dissociated free dumbbell $4-\mathrm{H} \cdot \mathrm{PF}_{6}$ from the dissociation study, plots of the [Rotaxane $^{-1}$ versus time can be obtained. The data, which were obtained (Fig. 2) from dissociations lasting 4-6 h, were best fitted to straight lines in agreement with second-order kinetics for both the a and $\mathbf{b}$ series. Rate constants $\left(k_{2}\right.$ and $\left.k_{-2}\right)$, dissociation rates and half-lives $\left(t_{1 / 2}\right)$ for the breakdown of $1 \mathbf{a} / \mathbf{b}-\mathrm{H} \cdot \mathrm{PF}_{6}$ were calculated and are listed in Table 1 . When comparing similar starting concentrations of the dynamic rotaxanes, in most cases, the stability to water dissociation of $\mathbf{1 a}-\mathrm{H} \cdot \mathrm{PF}_{6}$ is higher than that of $\mathbf{1 b}-\mathrm{H} \cdot \mathrm{PF}_{6}$. This observation may account for the enhanced template binding induced by translocational freedom involving the tetraethyleneglycol chain in 3a than that involving the more rigid 2,6-disubstituted pyridyl moiety in $\mathbf{3 b}$. 


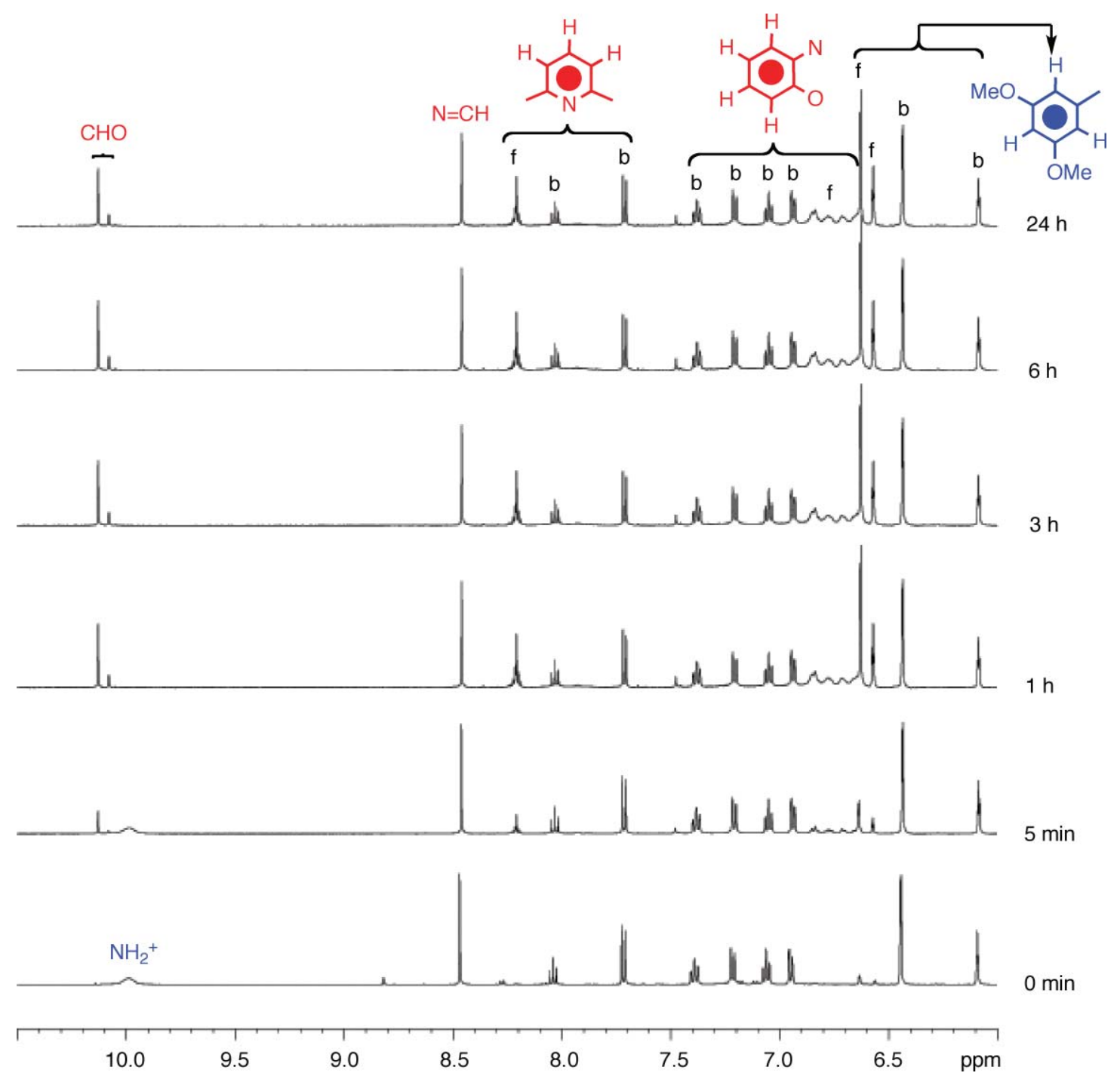

Fig. 1 Partial ${ }^{1} \mathrm{H}$ NMR spectra (aromatic region, $500 \mathrm{MHz}, \mathrm{CD}_{3} \mathrm{CN}, 298 \mathrm{~K}, 200 \mathrm{~mol}$ equivalents of $\mathrm{D}_{2} \mathrm{O}$, total conc. = $16.6 \mathrm{mM}$ ) showing the dissociation of the dynamic [2] rotaxane 1a-H.PF 6 with time $(\mathrm{b}=$ bound rotaxane and $\mathrm{f}=$ free components). With increasing time, the characteristic proton signals originating from the aldehyde $(\delta=10.12 \mathrm{ppm})$, the free (f) pyridine ring $(\delta=8.22 \mathrm{ppm})$ and the free (f) dimethoxyaryl ring $(\delta=6.62$ and $6.58 \mathrm{ppm}$ ) in separate cyclic (or acyclic) and dumbbell components were found to have their relative intensities increase while those signals arising from the rotaxane decreased. The results indicate that the dynamic [2]rotaxane dissociates slowly into its free components-2, 3a and 4-H.PF 6 -until the dissociation process has reached equilibrium after $24 \mathrm{~h}$. With particular reference to $1 \mathrm{a}-\mathrm{H} \cdot \mathrm{PF}_{6}$, there was $41 \%$ of the dynamic [2] rotaxane remaining in the mixture after $24 \mathrm{~h}$.

Table 1 Dissociation data of the dynamic [2]rotaxanes $\mathbf{1 a} / \mathbf{b}-\mathrm{H} \cdot \mathrm{PF}_{6}$ in the presence of water calculated from the ${ }^{1} \mathrm{H}$ NMR spectroscopic results

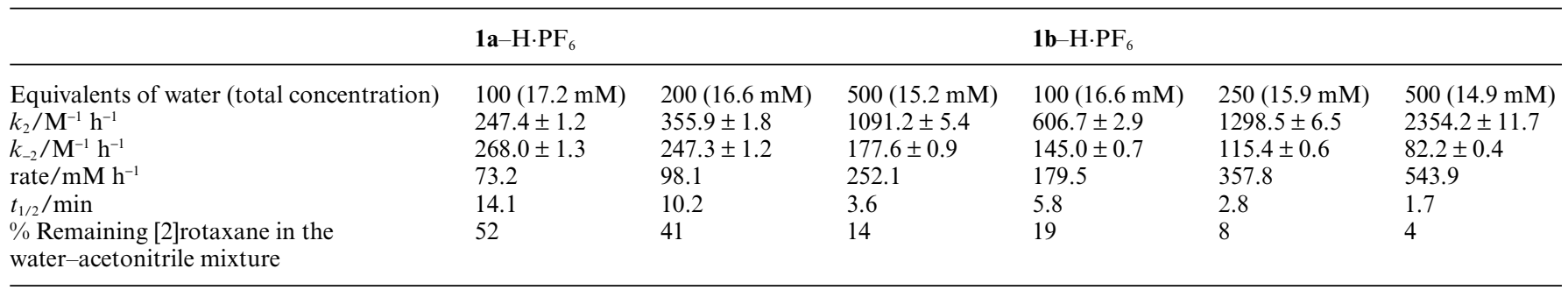

From a mechanistic point of view, the ring associated with the [2] rotaxanes $\mathbf{1 a} / \mathbf{b}-\mathrm{H} \cdot \mathrm{PF}_{6}$ will eventually open up (Scheme 2) with only one equivalent of $\mathrm{H}_{2} \mathrm{O}$ present in the solution to give the monoaldehyde intermediates $\mathbf{5 a} / \mathbf{b}$, allowing the dumbbell 4 $\mathrm{H} \cdot \mathrm{PF}_{6}$ to dethread from these intermediates on account of the loss of the crown ether's integrity and the associated pre-organisation. 


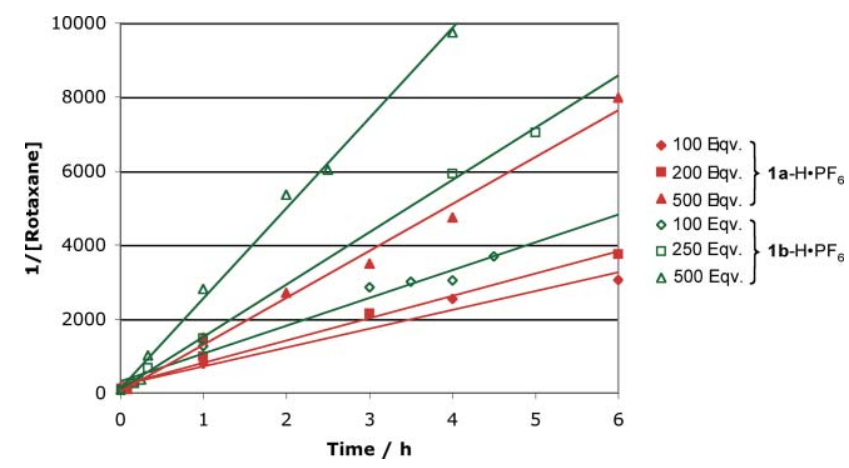

Fig. 2 A plot of [Rotaxane ${ }^{-1}$ versus time, showing the dissociation profile of the dynamic [2] rotaxanes $\mathbf{1 a} / \mathbf{b}-\mathbf{H} \cdot \mathrm{PF}_{6}$ in the presence of different amounts of $\mathrm{D}_{2} \mathrm{O}$. For the a series, the concentration of [2]rotaxane is 17.2, 16.6 and $15.2 \mathrm{mM}$ when 100,200 and 500 equivalents $\mathrm{D}_{2} \mathrm{O}$ were added, respectively. For the $\mathbf{b}$ series, the concentration of [2]rotaxane is 16.6, 15.9 and $14.9 \mathrm{mM}$ when 100,250 and 500 equivalents $\mathrm{D}_{2} \mathrm{O}$ were added, respectively. Data points were obtained from analyzing their ${ }^{1} \mathrm{H}$ NMR spectra $\left(500 \mathrm{MHz}, \mathrm{CD}_{3} \mathrm{CN}, 298 \mathrm{~K}\right)$. The data, which were obtained from dissociations lasting $4-6 \mathrm{~h}$, were best fitted to straight lines in agreement with second-order kinetics for both the $\mathbf{a}$ and $\mathbf{b}$ series.

Subsequently, the monoaldehyde intermediates $\mathbf{5 a} / \mathbf{b}$ will be hydrolysed even further right down to the diformylpyridine $\mathbf{2}$, as well as into the diamines $\mathbf{3 a} / \mathbf{b}$ with one additional equivalent of $\mathrm{H}_{2} \mathrm{O}$. However, the template effect offered by the multiple noncovalent interactions and also the stopper effect may retain the relative stability and integrity of the rotaxanes. That is, at equilibrium, relatively large amounts of $\mathrm{H}_{2} \mathrm{O}$ are required to hydrolyse the imine bond(s) and to solubilise the cleaved components.

Two control experiments were performed. Firstly, the dynamic [2] rotaxanes were dissolved separately in pre-dried $\mathrm{CD}_{3} \mathrm{CN}-$
DMF- $d_{7}(9: 1), \mathrm{CD}_{3} \mathrm{CN}-\mathrm{CD}_{3} \mathrm{OD}(2: 1)$ and pure $\mathrm{CD}_{3} \mathrm{CN}$. No significant changes were observed in the ${ }^{1} \mathrm{H}$ NMR signals, from which it was concluded that dissociation of the dumbbell $4-\mathrm{H} \cdot \mathrm{PF}_{6}$ does not occur even after standing for over $12 \mathrm{~h}$ in the presence of solvents that do not sustain hydrogen bonding. Secondly, since imine hydrolysis and formation can be catalysed by nucleophiles, ${ }^{8 b}$ as well as by acids, ${ }^{8 f, 16}$ the dissociations of the rotaxanes were investigated after adding a nucleophile — $p$-toluidine — as an imine exchange partner. On adding one equivalent of toluidine to the [2]rotaxane solutions, dissociation was found to occur on account of imine exchange, which results in the fast opening of the [24]crown-8 macrocycles to give the podand-like compounds $6 \mathbf{6} / \mathbf{b}$. Toluidine plays an important role in serving as a relatively bulky imine exchange partner with the macrocycle to give a disrupted open crown (podand), which cannot be easily converted back to the [24]crown- 8 derivative. As a consequence, the [2]rotaxanes dissociate rapidly on simply adding one equivalent of toluidine.

The reversible formation of the [2] rotaxanes $\mathbf{1 a} / \mathbf{b}-\mathrm{H} \cdot \mathrm{PF}_{6}$ from their separate components has been demonstrated (Fig. 3) by ${ }^{1} \mathrm{H}$ NMR spectroscopy. For example, from the dissociated mixture of the dynamic [2] rotaxane $\mathbf{1 a} / \mathbf{b}-\mathrm{H} \cdot \mathrm{PF}_{6}$ achieved on the addition of 200 equivalents of $\mathrm{H}_{2} \mathrm{O}$ (i.e., with $41 \%$ of the [2]rotaxane remaining in the mixture), after treatment with anhydrous $\mathrm{MgSO}_{4}$, the percentage of the corresponding dynamic [2]rotaxane $\mathbf{1 a} / \mathbf{b}$ $\mathrm{H} \cdot \mathrm{PF}_{6}$ is restored (Fig. 3a) to $\sim 70 \%$. Somewhat surprisingly, molecular sieves ( $4 \AA$ ) are not useful for drying these systems, since the dynamic [2] rotaxanes $\mathbf{1} \mathbf{a} / \mathbf{b}$ are unstable in their presence. Moreover, treatment with anhydrous $\mathrm{Na}_{2} \mathrm{SO}_{4}$, followed by evaporation and the redissolving of the dry $\mathrm{MeCN}$ (three consecutive cycles), gives (Fig. 3b) the corresponding dynamic [2]rotaxane 1a-H.PF . This reversibility of the equilibrium was found to be adjustable many times over, without destroying either the individual components or the dynamic [2] rotaxanes.

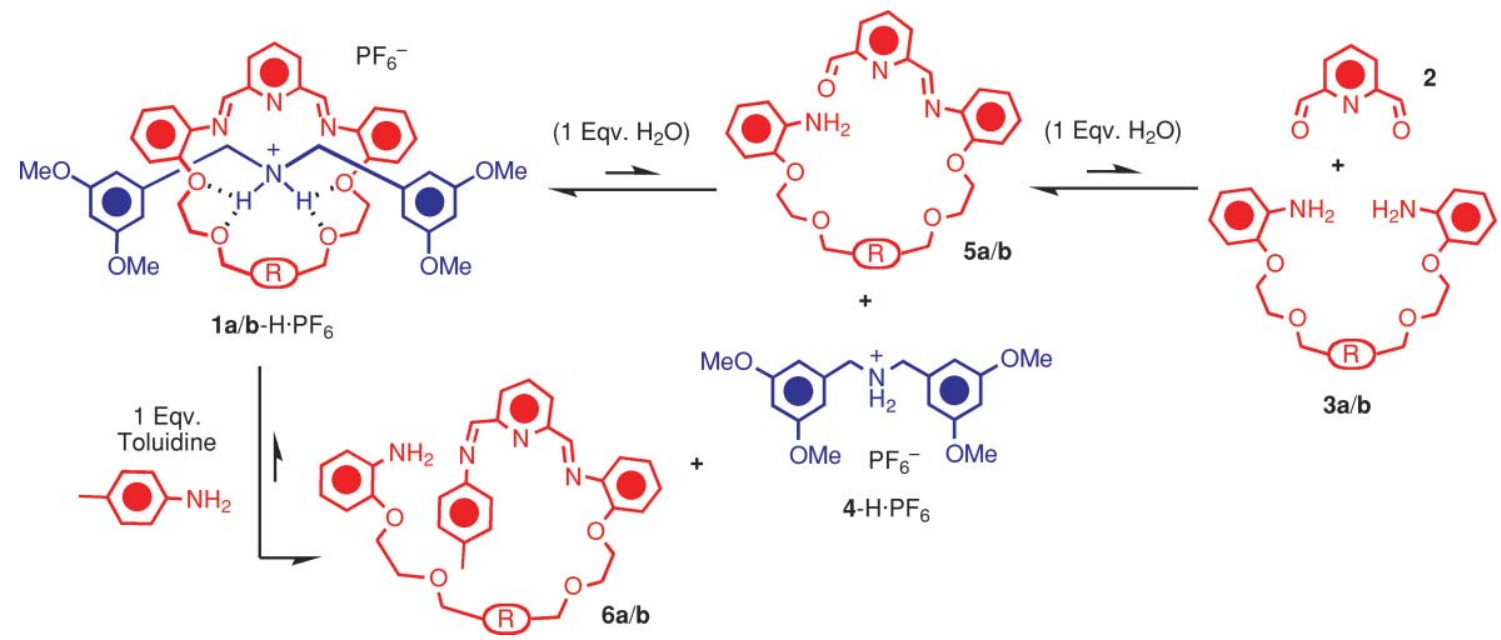

Scheme 2 Plausible mechanism for the dissociation of the dynamic [2] rotaxanes $\mathbf{1 a} / \mathbf{b}-\mathrm{H} \cdot \mathrm{PF}_{6}$ into their components $\mathbf{2}, \mathbf{3 a} / \mathbf{b}, \mathbf{4}-\mathrm{H} \cdot \mathrm{PF} \mathrm{F}_{6}, \mathbf{5 a} / \mathbf{b}$ and $\mathbf{6 a} / \mathbf{b}$. The ring associated with the [2] rotaxanes $\mathbf{1 a} / \mathbf{b}-\mathrm{H}_{\mathbf{P}} \cdot \mathrm{PF}_{6}$ eventually opens up with only one equivalent of $\mathrm{H}_{2} \mathrm{O}$ present in the solution to give the monoaldehyde intermediates $\mathbf{5 a} / \mathbf{b}$, allowing the dumbbell $\mathbf{4}-\mathrm{H} \cdot \mathrm{PF}_{6}$ to dethread from these intermediates on account of the loss of the crown ether's integrity and the associated pre-organisation. Subsequently, the monoaldehyde intermediates $\mathbf{5 a} / \mathbf{b}$ will be hydrolysed even further right down to the diformylpyridine $\mathbf{2}$, as well as into the diamines $\mathbf{3 a} / \mathbf{b}$ with one additional equivalent of $\mathrm{H}_{2} \mathrm{O}$. On the other hand, on adding one equivalent of toluidine to the [2] rotaxane solutions, dissociation occurs on account of imine exchange, which results in the fast opening of the [24]crown- 8 macrocycles to give the podand-like compounds $\mathbf{6 a} / \mathbf{b}$. Toluidine plays an important role in serving as a relatively bulky imine exchange partner with the macrocycle to give a disrupted open crown (podand) that cannot be easily converted back to the [24]crown-8 derivative. 

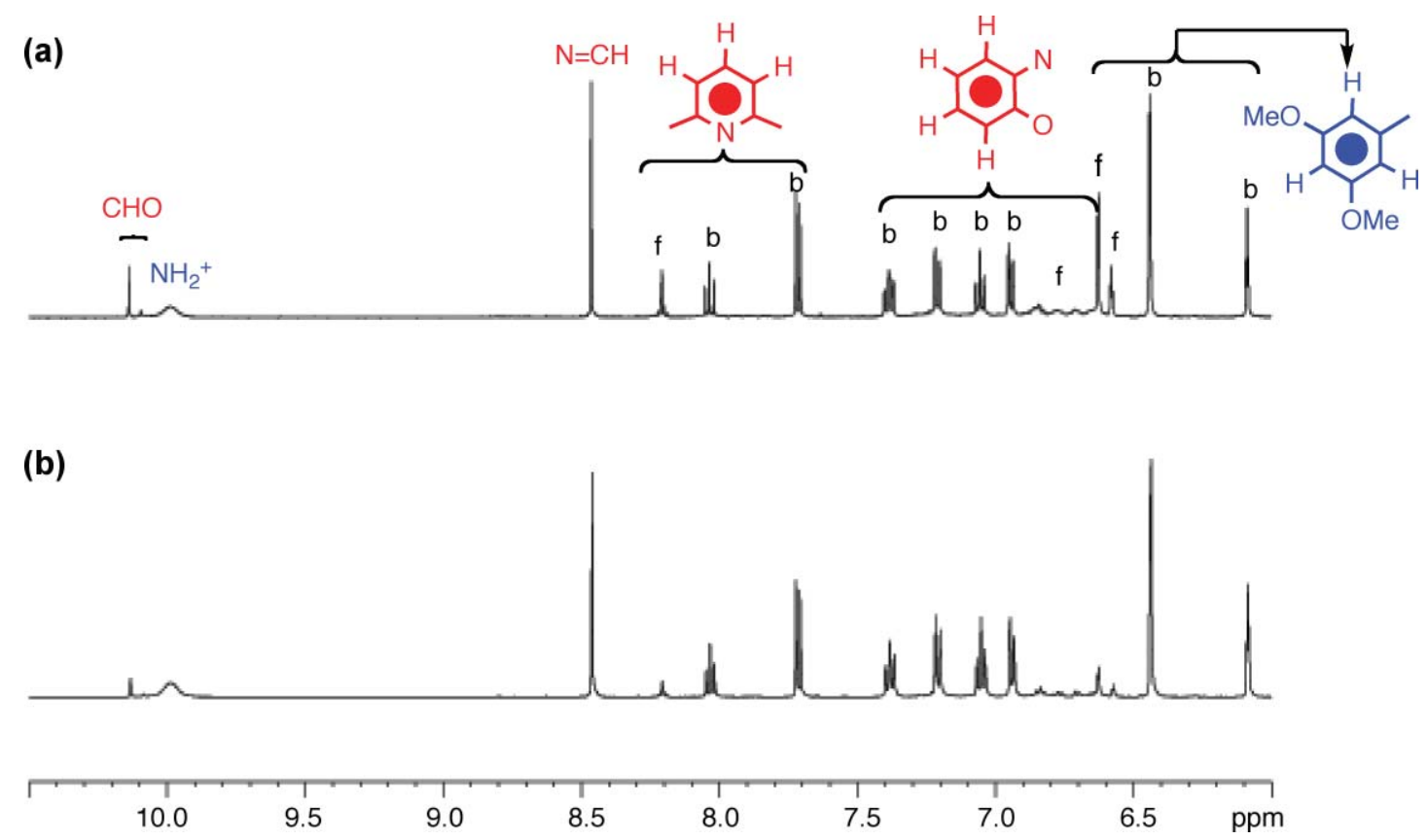

Fig. 3 Partial ${ }^{1} \mathrm{H}$ NMR spectra $\left(500 \mathrm{MHz}, \mathrm{CD}_{3} \mathrm{CN}, 298 \mathrm{~K}\right.$, aromatic region) of the dissociated dynamic [2]rotaxane $1 \mathrm{a}-\mathrm{H} \cdot \mathrm{PF} \mathrm{F}_{6}(\mathrm{~b}=\mathrm{bound}$ and $\mathrm{f}=$ free $)$ after treatment with (a) anhydrous $\mathrm{MgSO}_{4}$ and (b) anhydrous $\mathrm{Na}_{2} \mathrm{SO}_{4}$, evaporated and redissolved in $\mathrm{MeCN}$ through three consecutive cycles.

\section{Conclusions}

The separation of the dynamic [2]rotaxanes $\mathbf{1 a} / \mathbf{b}$ into their dumbbell and cleaved ring components in the presence of different concentrations of water has been demonstrated. Large amounts ( $>100$ equivalents) of water are required for the degradation of half of the molecules of the [2]rotaxanes. The stability of the [2]rotaxane $\mathbf{1 a}-\mathrm{H} \cdot \mathrm{PF}_{6}$ towards the hydrolysis is higher than that of $\mathbf{1 b}-\mathrm{H} \cdot \mathrm{PF}_{6}$. A mechanism for the hydrolysis, involving the hydrolytic cleavage of one of the two imine bonds in the [24]crown- 8 ring, has been proposed. It involves the formation of an acyclic intermediate following hydrolysis of one of the kinetically labile bonds in the ring. The separate components are also relatively stable in the presence of large amounts of water and can even be re-assembled to afford the dynamic [2] rotaxanes $\mathbf{1 a} / \mathbf{b}-\mathrm{H} \cdot \mathrm{PF}_{6}$, once again by eliminating water from their aqueous solutions. In principle, the concentrations of the dynamic [2]rotaxanes in the mixture can be controlled by the addition and subtraction of appropriate amounts of water. It is possible that by covalent attachment with fluorescent probes (reporter groups), such as anthracene or naphthalene moieties, detailed hydrolysis mechanisms for the degradation of these dynamic rotaxanes in the presence of various stimulie.g., water, acids, nucleophiles, etc. - could be investigated by monitoring the fluorescence quenching effects in the rotaxanes.

\section{Experimental}

\section{Materials and methods}

All reagents were purchased from Aldrich or Cambridge Isotopes Laboratories, Inc. 2,6-Pyridinedicarboxaldehyde (2) is commercially available, while tetraethyleneglycol bis(2aminophenyl)ether (3a) and bis-3,5-dimethoxybenzyl ammonium hexafluorophosphate $\left(4-\mathrm{H} \cdot \mathrm{PF}_{6}\right)$ were prepared according to literature procedures. ${ }^{8 c}$ The dynamic [2]rotaxanes were prepared according to the literature procedure, ${ }^{8 c}$ and were then dried in vacuo and isolated. Compound $\mathbf{3 b}$ was synthesized as illustrated in Scheme 3. Acetonitrile- $d_{3}(99.8 \% \mathrm{D}), N, N$-dimethylformamide$d_{7}(99.8 \% \mathrm{D})$ and methanol- $d_{4}(99.8 \% \mathrm{D})$ were dried with activated molecular sieves (4 $\AA$ ). Deuterium oxide $(99.9 \%$ D) was used. Thinlayer chromatography (TLC) was carried out using aluminium sheets, precoated with silica gel $60 \mathrm{~F}$ (Merck 5554). The plates were inspected by UV light, prior to their development with iodine vapor. Melting points were determined on an Electrothermal 9200 apparatus and are uncorrected. Column chromatography was performed on silica gel 60F (Merck 9385, 0.040-0.063 mm). All nuclear magnetic resonance (NMR) spectra were recorded on a Brüker Advance $500\left({ }^{1} \mathrm{H}\right.$ at $500 \mathrm{MHz}$ and ${ }^{13} \mathrm{C}$ at $\left.126 \mathrm{MHz}\right)$. Chemical shifts are reported in parts per million (ppm) downfield

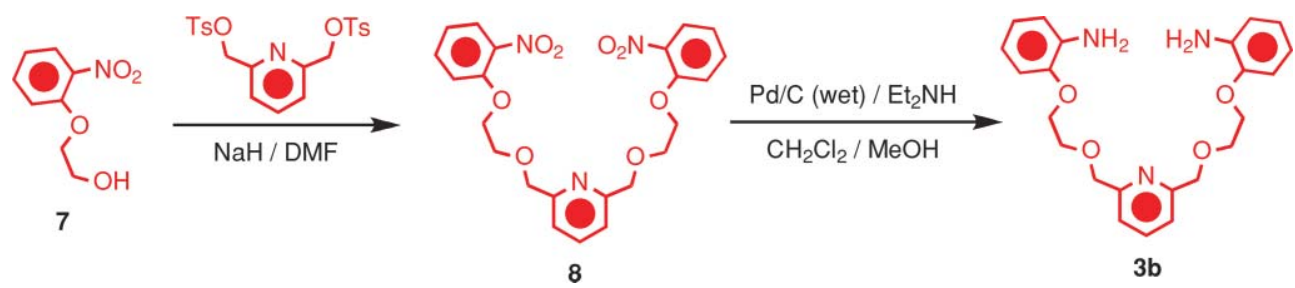

Scheme 3 Synthesis of the diamine compound $\mathbf{3 b}$ through an intermediate compound $\mathbf{8}$. 
from the $\mathrm{Me}_{4} \mathrm{Si}$ resonance as the internal standard for recording the ${ }^{1} \mathrm{H}$ and ${ }^{13} \mathrm{C}$ NMR spectra. High-resolution matrix-assisted laser-desorption ionization mass spectra (HR-MALDI-MS) were measured on an IonSpec Fourier Transform mass spectrometer. The reported molecular mass $(\mathrm{m} / \mathrm{z})$ values are for the most abundant monoisotopic mass.

\section{2,6-Bis[2-(2-nitrophenoxy)ethoxymethyl]pyridine 8. $\mathrm{NaH}$} $(0.13 \mathrm{~g}, 5.6 \mathrm{mmol})$ was added to a DMF $(20 \mathrm{~mL})$ solution of 2-(hydroxyethoxy)nitrobenzene ${ }^{17}$ (7) $(0.86 \mathrm{~g}, 4.7 \mathrm{mmol})$ and 2,6-bis( $p$-toluenesulfonyl)methylpyridine $(1.0 \mathrm{~g}, 2.2 \mathrm{mmol})$ in a three-neck round-bottomed flask. The mixture was heated at $90{ }^{\circ} \mathrm{C}$ for $18 \mathrm{~h}$. The solution was then cooled down to room temperature. The reaction mixture was added slowly to $\mathrm{H}_{2} \mathrm{O}$ $(500 \mathrm{~mL})$, and the resulting precipitate was filtered and dried to yield a beige solid. The crude product was purified by silica gel chromatography using $\mathrm{MeOH}-\mathrm{CH}_{2} \mathrm{Cl}_{2}(99: 1)$ as the eluent to yield the bisnitro compound $\mathbf{8}$ as an off-white solid $(0.32 \mathrm{~g}$, $30 \%$ yield); m.p. 90.2-92.4 ${ }^{\circ} \mathrm{C} .{ }^{1} \mathrm{H}$ NMR (500 $\mathrm{MHz}, \mathrm{CDCl}_{3}$ ): $\delta=3.94-3.96,(\mathrm{~m}, 4 \mathrm{H}), 4.30-4.32(\mathrm{~m}, 4 \mathrm{H}), 4.72(\mathrm{~s}, 4 \mathrm{H}), 7.02(\mathrm{t}$, $J=7.7 \mathrm{~Hz}, 2 \mathrm{H}), 7.11(\mathrm{~d}, J=8.3 \mathrm{~Hz}, 2 \mathrm{H}), 7.38(\mathrm{~d}, J=7.7 \mathrm{~Hz}$, $2 \mathrm{H}), 7.51(\mathrm{t}, J=7.6 \mathrm{~Hz}, 2 \mathrm{H}), 7.76(\mathrm{t}, J=7.7 \mathrm{~Hz}, 1 \mathrm{H}), 7.82(\mathrm{~d}$, $J=8.1 \mathrm{~Hz}, 2 \mathrm{H}) ;{ }^{13} \mathrm{C} \mathrm{NMR}\left(126 \mathrm{MHz}, \mathrm{CDCl}_{3}\right): \delta=68.7,69.1$, 74.1, 114.8, 120.2, 120.5, 125.5, 133.9, 137.6, 139.9, 152.1, 157.4; HRMS (HR-MALDI): calcd for $\mathrm{C}_{23} \mathrm{H}_{24} \mathrm{~N}_{3} \mathrm{O}_{8} \mathrm{~m} / z=470.1563$ and $\mathrm{C}_{23} \mathrm{H}_{23} \mathrm{~N}_{3} \mathrm{O}_{8} \mathrm{Na} m / z=492.1383$; found $m / z=470.1560[\mathrm{M}+$ $\mathrm{H}]^{+}$and $492.1383[\mathrm{M}+\mathrm{Na}]^{+}$.

2,6-Bis-[2-(2-aminophenoxy)ethoxymethyl]pyridine $3 \mathrm{~b}$. The bisnitro compound $8(0.40 \mathrm{~g}, 0.80 \mathrm{mmol})$ was dissolved in $\mathrm{CH}_{2} \mathrm{Cl}_{2}-\mathrm{MeOH}(10 \mathrm{~mL} / 10 \mathrm{~mL})$ in a $50 \mathrm{~mL}$ round-bottomed flask. Diethylamine $(0.4 \mathrm{~mL})$ and $\mathrm{Pd} / \mathrm{C}(50 \%$ water, $0.05 \mathrm{~g})$ were added, the reaction vessel was degassed and filled with $\mathrm{H}_{2}$, and the pressure was maintained at 1 atm for $4 \mathrm{~h}$. The catalyst was removed by filtration and the solution was evaporated in vacuo to give the title compound $\mathbf{3 b}$ as a clear oil $(0.33 \mathrm{~g}, 95 \%$ yield $) ;{ }^{1} \mathrm{H}$ NMR (500 MHz, $\left.\mathrm{CDCl}_{3}\right): \delta=3.93-3.94(\mathrm{~m}, 4 \mathrm{H}), 4.22-4.20(\mathrm{~m}$, $4 \mathrm{H}), 4.72(\mathrm{~s}, 4 \mathrm{H}), 6.67-6.72(\mathrm{~m}, 4 \mathrm{H}), 6.78-6.81(\mathrm{~m}, 4 \mathrm{H}), 7.38(\mathrm{~d}$, $J=7.7 \mathrm{~Hz}, 2 \mathrm{H}), 7.70(\mathrm{t}, J=7.7 \mathrm{~Hz}, 1 \mathrm{H}) ;{ }^{13} \mathrm{C} \mathrm{NMR}(126 \mathrm{MHz}$, $\left.\mathrm{CDCl}_{3}\right): \delta=68.1,69.3,73.9,112.6,115.2,118.3,120.1,121.7$, 136.6, 137.4, 146.2, 157.6; HRMS (HR-MALDI): calcd for $\mathrm{C}_{23} \mathrm{H}_{28} \mathrm{~N}_{3} \mathrm{O}_{4} m / z=410.2080$ and $\mathrm{C}_{23} \mathrm{H}_{27} \mathrm{~N}_{3} \mathrm{O}_{4} \mathrm{Na} m / z=432.1899$; found $m / z=410.2096[\mathrm{M}+\mathrm{H}]^{+}$and $432.1910[\mathrm{M}+\mathrm{Na}]^{+}$.

General procedure for investigating the dissociation of [2]rotaxanes. Typically, the [2] rotaxane $(10.0 \mathrm{mg}, 0.0107 \mathrm{mmol}$ for 1a$\mathrm{H} \cdot \mathrm{PF}_{6} ; 0.0103 \mathrm{mmol}$ for $\mathbf{1 b}-\mathrm{H} \cdot \mathrm{PF}_{6}$ ) was dissolved in $\mathrm{CD}_{3} \mathrm{CN}$ $(0.600 \mathrm{~mL})$ in an NMR tube. Prescribed amounts of $\mathrm{D}_{2} \mathrm{O}$ were added with a microsyringe. ${ }^{1} \mathrm{H}$ NMR spectra were recorded at specific times following the addition of water.

\section{Acknowledgements}

This material is based upon work supported by the National Science Foundation under CHE0924620 in the United States and by the RGC-GRF (CUHK401808) of Hong Kong SAR.

\section{Notes and References}

1 (a) P. A. Brady, R. P. Bonar-Law, S. J. Rowan, C. J. Suckling and J. K. M. Sanders, Chem. Commun., 1996, 319-320; (b) P. A. Brady and J. K. M.
Sanders, Chem. Soc. Rev., 1997, 26, 327-336; (c) J.-M. Lehn, Chem.Eur. J., 1999, 5, 2455-2463; (d) J. K. M. Sanders, Pure Appl. Chem., 2000, 72, 2265-2274; (e) L. M. Greig and D. Philp, Chem. Soc. Rev., 2001, 30, 287-302; $(f)$ R. L. E. Furlan, S. Otto and J. K. M. Sanders, Proc. Natl. Acad. Sci. U. S. A., 2002, 99, 4801-4804; (g) S. J. Rowan, S. J. Cantrill, G. R. L. Cousins, J. K. M. Sanders and J. F. Stoddart, Angew. Chem., Int. Ed., 2002, 41, 898-952; (h) P. T. Corbett, J. Leclaire, L. Vial, K. R. West, J.-L. Wietor, J. K. M. Sanders and S. Otto, Chem. Rev., 2006, 106, 3652-3711; (i) J.-M. Lehn, Chem. Soc. Rev., 2007, 36, 151-160.

2 (a) K. S. Chichak, S. J. Cantrill, A. R. Pease, S. H. Chiu, G. W. V. Cave, J. L. Atwood and J. F. Stoddart, Science, 2004, 304, 1308-1312; (b) K. S. Chichak, S. J. Cantrill and J. F. Stoddart, Chem. Commun., 2005, 3391-3393; (c) A. J. Peters, K. S. Chichak, S. J. Cantrill and J. F. Stoddart, Chem. Commun., 2005, 3394-3396; (d) C. D. Pentecost, K. S. Chichak, A. J. Peters, G. W. V. Cave, S. J. Cantrill and J. F. Stoddart, Angew. Chem., Int. Ed., 2007, 46, 218-222; (e) C. D. Pentecost, N. Tangshaivang, S. J. Cantrill, K. S. Chichak, A. J. Peters and J. F. Stoddart, J. Chem. Educ., 2007, 84, 855-859.

3 (a) K. C.-F. Leung, F. Aricó, S. J. Cantrill and J. F. Stoddart, J. Am. Chem. Soc., 2005, 127, 5808-5810; (b) K. C.-F. Leung, F. Aricó, S. J. Cantrill and J. F. Stoddart, Macromolecules, 2007, 40, 3951-3959; (c) K. C.-F. Leung, Macromol. Theory Simul., 2009, 18, 328-335; (d) K. C.-F. Leung, S. Xuan and C.-M. Lo, ACS Appl. Mater. Interfaces, 2009, 1, 2005-2012.

4 (a) A. R. Williams, B. H. Northrop, T. Chang, J. F. Stoddart, A. J. P. White and D. J. Williams, Angew. Chem., Int. Ed., 2006, 45, 6665-6669; (b) B. H. Northrop, N. Tangchiavang, J. D. Badjic and J. F. Stoddart, Org. Lett., 2006, 8, 3899-3902; (c) J. Wu, K. C.-F. Leung and J. F. Stoddart, Proc. Natl. Acad. Sci. U. S. A., 2007, 104, 17266-17271; (d) L. M. Klivansky, G. Koshkakavyan, D. Cao and Y. Liu, Angew. Chem., Int. Ed., 2009, 48, 4185-4189.

5 (a) F. Aricó, J. D. Badjic, S. J. Cantrill, A. H. Flood, K. C.-F. Leung, Y. Liu and J. F. Stoddart, Top. Curr. Chem., 2005, 249, 203-259; (b) K. E. Griffiths and J. F. Stoddart, Pure Appl. Chem., 2008, 80, 485-506.

6 For examples of rotaxane syntheses with ring closing metathesis, see: (a) J. A. Wisner, P. D. Beer, M. G. B. Drew and M. R. Sambrook, J. Am. Chem. Soc., 2002, 124, 12469-12476; (b) A. F. M. Kilbinger, S. J. Cantrill, A. W. Waltman, M. W. Day and R. H. Grubbs, Angew. Chem., Int. Ed., 2003, 42, 3281-3285; (c) F. Aricó, P. Mobian, J.-M. Kern and J.-P. Sauvage, Org. Lett., 2003, 5, 1887-1890; (d) J. D. Badjic, S. J. Cantrill, R. H. Grubbs, E. N. Guidry, R. Orenes and J. F. Stoddart, Angew. Chem., Int. Ed., 2004, 43, 3273-3278; (e) E. N. Guidry, S. J. Cantrill, J. F. Stoddart and R. H. Grubbs, Org. Lett., 2005, 7, 2129-2132; (f) H. Hou, K. C.-F. Leung, D. Lanari, A. Nelson, J. F. Stoddart and R. H. Grubbs, J. Am. Chem. Soc., 2006, 128, 1535815359.

7 For rotaxane-containing disulfide units in their dumbbell-shaped components that are formed by riveting and stoppering approaches, see: (a) A. G. Kolchinski, N. W. Alcock, R. A. Roesner and D. H. Busch, Chem. Commun., 1998, 1437-1438; (b) Y. Furusho, T. Hasegawa, A. Tsuboi, N. Kihara and T. Takata, Chem. Lett., 2000, 18-19; (c) T. Oku, T. Furush and T. Takata, J. Polym. Sci., Part A: Polym. Chem., 2003, 41, 119-123; (d) Y. Furusho, T. Oku, G. A. Rajkumar and T. Takata, Chem. Lett., 2004, 33, 52-53.

8 (a) S. J. Cantrill, S. J. Rowan and J. F. Stoddart, Org. Lett., 1999, 1, 1363-1366; (b) S. J. Rowan and J. F. Stoddart, Org. Lett., 1999, 1, 1913-1916; (c) P. T. Glink, A. I. Oliva, J. F. Stoddart, A. J. P. White and D. J. Williams, Angew. Chem., Int. Ed., 2001, 40, 1870-1875; (d) M. Horn, J. Ihringer, P. T. Glink and J. F. Stoddart, Chem.-Eur. J., 2003, 9, 4046-4054; (e) F. Aricó, T. Chang, S. J. Cantrill, A. I. Khan and J. F. Stoddart, Chem.-Eur. J., 2005, 11, 4655-4666; (f) C. D. Meyer, C. S. Joiner and J. F. Stoddart, Chem. Soc. Rev., 2007, 36, 1705-1723; (g) P. C. Haussmann, S. I. Khan and J. F. Stoddart, J. Org. Chem., 2007, 72, 6708-6713; (h) P. C. Haussmann and J. F. Stoddart, Chem. Rec., 2009, 9, 136-154.

9 (a) C. Godoy-Alcántar, A. K. Yatsimirsky and J.-M. Lehn, J. Phys. Org. Chem., 2005, 18, 979-985; (b) W. Lu and T. H. Chang, J. Org. Chem., 2001, 66, 3467-3473; (c) T. Hirashita, Y. Hayashi, K. Mitsui and S. Araki, J. Org. Chem., 2003, 68, 1309-1313.

10 V. Saggiomo and U. Lüning, Eur. J. Org. Chem., 2008, 43294333.

11 A. Simion, C. Simion, T. Kanda, S. Nagashima, Y. Mitoma, T. Yamada, K. Mimura and M. Tashiro, J. Chem. Soc., Perkin Trans. 1, 2001, 20712078. 
12 M. Hutin, C. A. Schalley, G. Bernardinelli and J. R. Nitschke, Chem.Eur. J., 2006, 12, 4069-4076.

13 S. Nygaard, K. C.-F. Leung, I. Aprahamian, T. Ikeda, S. Saha, B. W. Laursen, S.-Y. Kim, S. W. Hansen, P. C. Stein, A. H. Flood, J. F. Stoddart and J. O. Jeppesen, J. Am. Chem. Soc., 2007, 129, 960-970.

14 S. Saha, K. C.-F. Leung, T. D. Nguyen, J. F. Stoddart and J. I. Zink, Adv. Funct. Mater., 2007, 17, 685-693.
$15 \mathrm{D}_{2} \mathrm{O}$ was employed instead of $\mathrm{H}_{2} \mathrm{O}$ because of the ease for ${ }^{1} \mathrm{H}$ NMR spectroscopic characterization. Notice that the dissociation of the [2]rotaxanes in $\mathrm{H}_{2} \mathrm{O}$ would proceed faster than those in $\mathrm{D}_{2} \mathrm{O}$ because of the isotope effect.

16 R. W. Layer, Chem. Rev., 1963, 63, 489-510.

17 T. Ventrice, E. M. Campi, W. R. Jackson and A. F. Patti, Tetrahedron, 2001, 57, 7557-7574. 